\title{
En Lernedstegning.
}

Min Farbroder Ha ns Peter $\mathrm{Ha}$ as se n, af hvis skriftligt efterladte Erindringer "Sonderjydske Aarboger" bringer et Afsnit, blev folt paa Norremølle den 7 . Januar 18:8. Han blev af sine Saskende skildret som en ualmindelig begavet Dreng, hvis Evner og Anlæg tidlig vakte Opmærksomhed.

Fem Aar gammel kom han i Skole i Snogbæk. Undervisningen var rent dansk, men ved Siden af gik han i tysk Aftenskole, og udenfor Skoleticlen læste han alt, hvad han kunde faa fat i. Hans Fader holdt foruden "Sønderborg Ugeblad" "Itzehoer Nachrichten« og "Aarhus Stiftstidende«. Dem laste han, men Bladene var smaa, og Bøger var der ikke mange af, Ofte klagede hall sig derfor i sine Drengeaar over, at han ikke havde noget at lase i. "Tag Bibelen«, var da altid hans Faders korte, fyndige Svar.

Hans Fader Christen Hanssen havde to Caarde, Norremølle i Sottrup Sogn og fra 1834 tillige Ravnsk obbel i Dybbol sogn. Ved Siden af drev han Bræudevinsbrænderi, Maltgoreri og en betydelig Landhandel. Dertil kom endıu fra 1837 (rundlæggelsen af et bajersk (xlbryggeri, hvortil han indkaldte en Brygnester fra München. Men dette maatte han atter standse efter nogle Aars Forløb, da Afswtningen viste, at det var et for tidligt fodt Foretagende. En gammel Nabo udtrykte sin Beundring for hans Driftighed i folgende Rim:

\footnotetext{
Ned' ved christen i at Sek Der ha' de Skik.

Jen bruer, og jen brender.

Jen loffer, og jen render, Olt garer i a fuld ros. Ja!
}

Dette driftige Liv vakte tidlig Sonnens Interesse for Forretningslivet og gav ham Lyst til at lare Handelen. 
Hans Fader mente, at han passende kunde udstaa sin Læretid i Nordborg, men det satte han sig, som det fremgaar af hans foran trykte Erindringer, imod med Hander og liodder. Han vilde lare under storre Forhold, fik ogsaa sin Vilje og kom efter sin Konfirmation, 15 Aar gammel, i Lare hos Firmaet A. P. A ndresen i Flensborg, hvis Indehaver C.aspar Andresen val en son af A ndreas Peter $\Lambda$ uresen, den bekendte Storkobmand og Patriot, som i forrige Aarhundredes forste Halvilel saa smukt tolkede sine valme danske lolelser paa flydende tỵske V'ers.

Læretiden var lang og streng, men de flensborgske Handelslærlinge blev til Gengald meget velskolede Forretningsmænd. Fritiden var knap. Desuagtet fandt han stunder til at lere Engelsk og dobbelt Bogholderi, som ikke var indfort i Forretningen. Efter uistaaet Leretid blev han hos firmaet. Men saa kom Oproret i 1848. Hans Principal sluttede sig til Slesvigholstenerne, mens hall var udpraget dansksindet, og det gode Forhold, der hidtil havde bestaaet mellem dem, blev delved ødelagt. Efter Slaget ved Bov, som han oplevede paa nart Hold, skappedes Modsatningerne. Det endte, som i hans Erinclringer fortalt, ned et fuldstrendigt Brul, og de skiltes $i$ Vrede fra hinanden. Efter flere Aars Forlob genoprettedes Forholdet dog, og han vedblev til sin Dod at staa i venskabelig Forbindelse med sin gamle Principals Siøn, tidligere l)irektor for Jernskibsværftet i Flensborg, Hr. Andresen.

Da Bruddet indtraadte, var min Bedstefader afgaaet ved Doden, efterladende sig en efter Tidens Forhold betydelig Formue. Skønt Soskendeflokken var stor, - 5 Souner og 5 Intre - kom H. P. Hanssen derved i Besiddelse af en Arvepart paa 15,000 Mark Courant. Trangen til at komme ud under storre Forhold rorte sig atter i ham. Det ny opdagede Guldland Kalifornien virkede isuer dragende. En Annonce i triske Blade henledte hans Opmærksomhed paa et tysk Selskab i Hamborg, som vilde fragte et Sejlskib til St. Francisko. Han traadte $i$ Forbindelse med Selskabet, indhentede, saa godt det lod sig gore, narmere Efterretuinger, kobte terefter Varer, isar Mobler og Lre, 
for sin Arvepart, indskibede sig med dem i Hamborg, og drog saa ud $\mathrm{i}$ den vide Verden for at suge Lykken.

Efter seks Maaneders Sorejse landede han i 1850 i st. Franrisko, hvor han sammen med ell Kompagnon, som hall havde lart at kende paa Overrejsen, aabnede en Forretning. Men han lavile ikke Held ned sig. Byel,, som den Gang kun bestorl af 'rrehuse, nedbrande to Gange i Lobet af kort Tid. Forste Gang led han betydelige 'Tab, anden Gang mistede han alt, hvall han ejede.

For nin Farbrocler H. P. Hanssen var taget til Kalifornien, havie han truffet den Aftale med min Fader, at de vilde skrive til hinanden i hver Maaned, uden Hensyn til, om Brevene blev besvarede eller ej, indtil den ene erfarede, at den anden var afgaaet ved Doden. Denne Aftale holdt de, indtil min Fader chole i 189:. Min Farbroder meddelte mig den Gang, at allo min Faders Breve, som han havde opbevaret fra det forste til det sidste, vilde blive mig tilsendt efter hans Iod, og de er nu i min Besiddelse, ligesom de Breve, han har skrevet til mit Hjem. Indtaget herfra er $\log$ en Rrkke Breve fra Kina om Taiping-Oproret, som min Fader efter Anmodning gav "Danuevirke«s daverende Redaktør Tilladelse til at aftrykke i Bla(let. $\left.{ }^{*}\right)$

Næppe havile min Fader i 1851 erfaret sin Broder's Ulykke, for han straks sendte ham en efter hans Forhold betydelig sum, for at han atter kumde komme i Vej. Men H. P. Hanssen havile nu faaet nok af St. Francisko. En Tur til Sandwichswerne med et seks Ugers Ophold i Honolulu overbeviste ham om, at Forholdene der heller ikke var gunstige for en Forretningsmand ned hans Forudsatninger. Paa den lange Surejse til st. Francisko, havcle han sluttet Venskab med Kaptajnen, som derefter var gaaet i Fart fra Amerika til Wstasien. Efter hans Raad tog han saa over Oceanet til Kina, hvor hall henventte sig til den daværende danske Konsul $\mathrm{B}$ l o ch i Honkong,

* Disse Breve (r trykt i "I)annevirke Nr. 251, 25: og 253 1854 og Nir. $: 0.51855$. 
der tog meget velligt imod ham og gav ham Ansættelse, indtil der bod sig noget bedre. Med Konsul Blochs Hjælp fik han derpaa nogle Maaneder senere Plads som Bogholder i Firmaet Sykes, Sch wab \& C.o. i Shanghai.

Med Konsul Bloch, hvis Datter var gift med Bankdirektør He i d e, vedblev $H$. P. Hanssen senere at staa i venskabelig Forbindelse. Han bessgte ham gentagne Gange i Honkong. og senere, efter at Konsulen var taget tilbage til Danmark, hver Gang, han val hjemme i sundeved, paa Konsulens bekendte Villa, „Kokkedal“ ved Øresund.

Da H. P. Hanssen 1852 ankom til Shanghai, var der ialt kun henved 300 Europaere, næsten udelukkende Englændere, i Byen. I dette lille samfund, som helt var præget af Tonen i det høje engelske Handelsaristokrati, og hvis Medlemmer alle betragtede hinanden som Ladies og Gentlemen, vandt han hurtig Anerkendelse som en dygtig og indsigtsfuld Forretningsmand.

I Folelsen af, at hans Dannelse var altfor mangelfuld, kastede han sig i sin Fritid med Jernflid over nye Studier, der ikke blot onfattede Handelsvidenskaberne, men ogsaa Historie, Litteratur, Flansk, som han senere talte flydende, og $L$ a $\mathbf{t}$ i $n$, som han holdt det for nodvendigt at lære for ikke at staa tilbage for sine paa Englands beromte Skoler uddannede Kollegaer.

Ved Nytaarstid 1855 blev han en Dag behagelig overpasket ved et Besøg af Mr. E. W e b b, en af Cheferne for D e $t, B$ e a I e \& C.o., den Gang Wstasiens næststørste Handelshus, som opfordrede ham til at indtræde som Assistent i Huset. Tilbudet var meget smigrende. Han modtog det med Glæde, overtog sin nye Stilling i Maj samme Aar og avancerede hurtigt frem til mere betroedle Poster. 'I 1858 blev han Hovedbogholder i Shanghai med en Lon af 1000 Pund Sterling og fri Station.

De l, Beale \& Co. havde deres egen store Bygning, hvoraf Halvielen senere er bleven solgt for 40,000 Pund Sterling til «Russisk-kinesisk Bank» (den russsiske Statsbank). Cheferne og Funktionæreme havile alle deres Værelser i Huset, der nasten var indrettet som Hotel. De modtes ved Frokostbordet 
Kl. 9, derefter samledes de atter til Lunch, bestanende af to varme Kodretter, Budding og Dessert KI. 11/2, og til Diner Kl. 71/2. Til Dineren maatte de mode i Selskabsdragt. Der serveredes Suppe, Fisk, to varme Kodretter og Dessert, dertil Ale, Sherry, Rodvin og lidt Champagne, til Desserten fin Rodvin, Sherry og Portvin, og til Kaffen Likurer. Saaledes var den daglige Levemaade $i$ det store Handelshus! Der. blev holdt aabent Hus og var hyppigt Gester til stede, især Officerer fra Krigsskibe, som anlob Havnen.

I slutningen af Halvtuedseme aabnede Lord Elgins Traktater den engelske Handel en Hække nye Havne i Kina og Japan, og Dent, Beale \& Co. sogte straks at udnytte Chancerne. Dette havde bl. a. til Folge, at H. P. Hanssen i Maj 1859 blev forfremmet til Husets Repræsentant i $C: \mathrm{h}$ i f o o, hvor det grundlagde en ny Filial. Derfra kom han til W e i ll a i-w e $i$, hvorfra han i 1860 fik et Aars Hjenılov med halv Gage. Han rejste over Japan, hvor han aflagde Besug i N a g s a k i og Y o k o ha ma, og herfra over Houk ong, Singapore, Ceylon, A den, Ka i ro, A l exandria, Triest, Venedig, Lyou, Patr is, L o n d on, hjem til Sundeved, hvor han overraskede sine Suskende med rige Gaver af sjolden $\Lambda$ rt, som han havde købt 1 de uy aabnede Havne i Japan.

Id paa Efteraaret rejste han atter over Marseille, A lexandria, Suez, Honkong ud til shanghai, hvorfra han blev sendt til T i e $n \mathrm{t}$ s in som Dent, Beale \& Co. Representant i demne Br. Fra 'lientsin besogte han Pek i $\mathbf{g}$. men i 1862 blev han atter kaldt tilbage til Shanghai og forfremmet til Kontorchef. Hans Stilling var lidt efter lidt bleven glimrende. Han havie paa lette Tidspunkt en fast Gage af 2000 Pund Sterling, dertil fri Station og Ret til for egen Regning at handle med The og alle Varer, som Huset ikke forte. Han spekulerede med Held i Bygninger, anlagde ot Teglvark og drev betydelig Handel for egen Regning.

I 1864 afgik en af Husets fem Partnere ved Dølen, og han blev da af de ovrige Partnere opfordret til at indtrade som Partner i hans Sted. Tilbudet var overordentlig smigrende. 
Men det var alligevel med store Betænkeligheder, at han modtog det, thi hans Stilling var udmerket, og Husets Forretninger var saa udstrakte, at det ikke var muligt at overskue dem i alle Enkeltheder.

De n t o g C o., som Firmaet nu hed, efter at Mr. Beale var afgaaet ved Doden, drev Forretninger over hele Ostasien. Hovedkvarteret og med det Hovedbogføringen var i Honk o $\mathrm{n}$, hvor der altid var 2 eller 3 Partnere. Derfra styredes Handelen fra Bombay og Kalkutta med Opium, Ris og Bomuld til Singapora, Manila og A ustralien. Handelen paa Australien blev isar vigtig efter Guldminernes Opdagelse. Der afskibedes ismer The fra $\mathrm{Foovsch}$ ow. Rimesserne fra $\mathrm{Au}$ stralien skete hyppigt $\mathrm{i}$ Kobber til Kalkutta. Endvidere havde Dent \& Co. Filialer og Stationer i følgende Havne og Byer: shanghai, Kanton, Capsingmore, swatow, Amoy, Chinchew, Fooschow, Takao, Woosung, Ningpo, Chinkiang, Hankow, Chifoo, Tientsin, Newchwang, Nagasaki, Yokohama og Hakodate. Desuclen havde Huset seks Dampskibe og talrige Sejlskibe i Fart. Fra Honk ong dirigeredes Stationeme i foos chow, A moy, Formosa, og Kanton, fra Shanghai, livor der igeledes var 2 eller 3 Partnere, alle stationer fra rooschow nordpaa samt stationerne i Japan.

Hovedartiklerne var The og Silke. Theen afskibedes fra Hankow-Kiangkiang-Shanghai til London og New York og Australien. Silken afskibedes fra Shanghai og Yokohama til London og Lyon. Partnerne i Hongkong og Shanghai foretog selvfolgelig alle vigtigere Operationer $i$ Fallesskab.

I dette rige, højt ansete og ver(lensberomte Handelshus indtraadte H. P. Hanssen nu, tolv Aar efter at han med bare Hænder var ankommen til Hongkong efter indtrangende Opfordring fra Partnerne, og han var dermed bleven ell af Husets fem ledende Chefer. Dette var en for en Ikke-Englender ganske usiedvanlig Lobebane. Forretningerne var i Halvtredserne og først i Tredserne gaaet glimrende. Partnerne havde efter faa Aars Virksomhed kumnet trakke sig tilbage som rige 
Mand. Og allerede $i$ Besiclelse af en Formue paa henved en kvart Million Kroner havie han, som han selv skriver, nu Ldsigt til om 3 \& Aar at kumle forlacle Kina som Millionar.

Men det kom anderledes. Husets Kapital var paa dette Tidspunkt ca. 500,000 Pund sterling. Men de tidligere Partnere var forpligtede til at lade deres Kapital blive staaende i Huset i mindst tre Aar efter, at de var udtraadte, og da disse Kapitaler forrentedes med $8 \%$, var de meget villige dertil. Som Folge deraf disponerede Huset i 1863 ialt over $21 / 4$ Million Pund sterling. Dertil kom nu yderligere, at Husets Reprasentant $i$ London, De $u$ t, Palmer \& Co. gav det en saa udstrakt Blancokredit, at det ofte stod i lorskud med henved 1/2 Million rund Sterling uden at have mindste Draning. Efter at cle nye Traktater forst $i$ Tredserne havole aabnet Handelen talrige nye Havne i Kina og Japan, forledte deme Kapitalrigdom Dent \& (co., hvis Skibe var de forste, der viste det engelske Handelsflag i Japan, til at binde meget betrilelige Kapitaler i Byguinger paa alle de Pladser, hvor de var repræsenterede, og i hurtigtgaaen(le Iampskibe, som de lod bygge i Amerika. Dette havnede sig dyrt, da der i 186 it unbrod en financiel Verdenskrise.

Partuerue i Dent \& Co. var i 1864, da H. P. Hanssen indtraadte som fente Mand, Joh n De nt, F. C:holnley, Alex. T u r ing (fra Rotter(lam) og He $\| \mathrm{r}$. W. I) e $\| \mathrm{t}$. De to forste resiclerede i Hongkong, ' $\mathrm{l}$ u $\mathrm{l}^{2} \mathrm{i} \| \mathrm{g}$ og H. P. H a $\| \mathrm{s}$ s e $\|$ i Shanghai, Henry W. De $\| \mathrm{t}$ var i England. J o h " D e nt, som var en meget rig Mand, havde forst i Tredserne sammen med en ArtiJeri-Officer B lakely grumdlagt et Kanonstoberi i England, som var baseret paa ón af Flakely opfunden Kanon. Forelagendet mislykkedes. Der tabtes uhyre summer, og Folgen var ikke blot, at John Dent i 1 K(b5 saa sig Ilodsaget til at trakke benved 1/4 Million Pund sterling ud af Huset, men hvad del. var varre, at han tillige tilsatte sin Anseelse som lorretningsmand og derved svakkede Husets Kredit i England.

Der meldte sig suart andre ranskeligheder. En kostbar Ladning The, som ikke var assureret, da Huset stod sin egen lisiko, gik tabt ved skibbrud. Og samne Aar opdagede H. P. 
Hanssen, at Hovedbogholderen i Shanghai, en Portugiser verl Navn Loureiro, havde forfalsket Bogerne og gjort sig skyldig i meget omfattende Bedragerier. Ved en Ekstra-Revision! konstateredes der straks en enkelt Forfalskning paa 33,000 Pund Sterling. Og nu kom det værste: Den følgende Nat stjal og tilintetgjorde Loureiro Husets vigtigste Handelsbøger. Ha!n blev fxngslet og senere for Falsk, Bedrageri og Inderslab domt til 15 Aars Deportation til Loando, men Huset havde ved hans Svig lidt et samlet Tab paa 166,000 Pund Sterling, som var uerstatteligt, skønt der forelaa en til Vished gransende Formodning om, at Loureiro ved en Broders Hjalp havde bragt hetydelige Kapitaler i sikkerhed, før Bedrageriet opdagedes.

Det viste sig nu at være i høj Grad uheldigt, at Huset havile bundet saa betydelige Kapitaler i Bygninger og skibe. For at klare Vanskelighederne maatte det sælge to til Fartell paa Jangse-Hankow kort forinden i Amerika byggede Dampskibe for 170,000 Pund sterling, det vilde sige med et Tab paa over 50,000 Pund Sterling. Næppe var dette Skær klaret, for der $i$ Maj 1866 udbrød en meget alvorlig Handelskrise i London, som hurtigt rev flere store Banker overende og forplantede sig helt ud til Xstasien. The og Silke faldt brat og uventet meget betydeligt i Pris, og Dent \& Co., som havde meget betydelige Sendinger undervejs til Europa, led atter uhyre Tab. Husets Repræsentant i London, De n t, Palmer \& Co., som med stigende Opmarksomhed havde fulgt dets Kamp imod alle disse sammenstodende Ulykker, trak nu forsigtigt sin BlancoKredit tilbage, og Dent \& Co. var dermed ude af Stand til at klare sine Forpligtelser. Efter flere Maaneders haabløse Kampe gik det stolte Handelshus i 186 f fallit, og dermed mistede $H$. P. Hanssen for tredje Gang alt, hvad han ejede.

Min Fader havde gennem sin Broders maanedlige Breve kunnet følge clenne I'dvikling, og næppe havde han af et Telegram til et hamborgsk Børsblad erfaret Husets Fallit, for hall uden Opfordring og uden at kræve mindste sikkerhed sendtr? sin Broder 6,000 Rigsdaler, som H. P. Hanssen modtog, hva.l jeg her kun anforer som Bevis paa det trofaste Sammenhold or 
lijertelige, tillidsfulde Forhold, der i god Overensstemmelse med slagtens Traditioner bestod mellem Brodrene.

Inder alle disse Genvordigheder havde $H$. P. Hanssen heldigvis hævdet sin .Ere som en retskaffen, kyndig og fremragende dygtig Forretningsmand. Paa Børsen i Hamborg udtalte man, at han var den eneste af Husets Chefer, som ikke havde tabt Hovedet under Ulykken. Han blev valgt til at forestaa Husets Likvidation og var optaget deraf i de folgende Aar.

I 1805 var A l fred Den t $i$ en Alder af 21 Aar kommen til Kina, for efter nogle Aars lorløb forudgaaende videre Uddannelse i Dent \& Co. at aflose en af sine Slægtninge son Partner i Huset. I 1869 opfordrede han H. P. Hanssen til sammen med ham at grundlagge en ny Forretning. Alfred Dent raadede over en Kapital paa 80,000 Pund sterling og dertil vardifulde Forbindelser indenfor det rige londonske Handelsaristokrati. idet han var en Søn af en af Cheferne for De nt, Pal mer Co. H. P. Hanssen modtog 'rilbudet og grundlagdle saa i 1869 sammen med Alfred Dent det endnu i Shanghai bestaaende Handelshus A If red Dent \& Co.

Alfred Dent \& Co. maatte, sammenlignet med Dent \& Co., begynde under beskedne Forhold, da dets Pengemidler var begrænsede. Men det overtog Dent \& Co.s anselige Hus i Shanghai og udnyttede dets gamle Forbindelser. Handelen gik godt, og efter at Alfred Dent i 187: ved sin Fader's Dod havile faaet en betydelig Arv og stillet Halvdelen af den til Husets Disposition, var det $i$ stand til at udvide Forretningerne meget betỵdeligt.

I 18 i3 aflagde H. P. Hanssen atter et Besog i sit Hjem $i$ Sundeved. Han tog Ruten over Alexandria, Venedig, W i e $n$, hvor han besøgte Verdensudstillingen, L o nd o $n$, hvor han blev meget vel moitaget af Alfred Dents liøjt ansete Slægt, hjem. lra Nørremolle aflagde han i Sommerens Lob Besøg hos Slægtninge i Norge, Celle og Gottingen og hos Forretningsvenner i Rotterdam og England. Udrejsen foregik via Brindissi til B o m b a $y$, hvor Alfred Dent \& Co. førte betydelige Forretninger, og derfra til $\mathrm{Sh}$ anghai. I de folgende $\Lambda$ ar 
handlede Huset vedvarende heldigt, og midt i IIalvfjerdsrrme havde H. P. Hanssen atter tjent en Formue, som var stor nok til, at han kunde tanke paa at vende Kina Ryggen.

I 1876 udlob hans Partnership. Alfred Dent foreslog ham at forlange det. Men trat af Opholdet $i$ Kina, hvor han nu havde levet $i 24$ Aar, onskede han at trakke sig tilbage til London, saa meget mere, som suezkanalen midt i Halvfjerdserne havde drabt Storhandelen, som den hidtil var fort i Kina, og han frygtede for komnende Vanskeligheder. A If re if I) e $\mathrm{t}$, som imidlertid i 1875, sammen med en yngre Broder Ed var 1 De nt, der dog ikke aktivt leltog i Forretningen, endvidere $i$ London havde grundlagt Huset De n t, B r o th e r \& C o., opfordrede H. P. Hanssen til at indtage en ledende Stilling i dette Hus, og dette Tilbud tog han inıod. Ud paa sommeren $1876^{\circ}$ forlod han derpaa Kina for over J a p I og St. Francisk o efter et Par Maaneders Ophold i Amerika at gaa tilbage til London, hvor han ankom henimod Aarets slutning.

Dent. Brother \& Co.s vigtigste Handel var The fra Ceylon. Mens H. P. Hanssen ledede den, fortsatte A 1 f red D e n med en ny Partner Huset A 1 f red De n t \& C o. i Shanghai, og han blev snart optaget af mange andre Forretninger.

En gammel Bekendt af H. P. Hanssen, B a r o n O verb e c k, østrigsk-ungarsk Generalkonsul i Kina og Japan - om hvem mere senere havde i 1875 afsluttet Traktater med ile uafhæengige Rajaher og Sultaner af Nord Borneo, hvorved de imod en aarlig Afgift afstod et Distrikt paa 20,000 engelske Kvadratmil til ham med Ret til videre Overdragelse. Overbeck, som før havde været ansat i Dent \& Co., var selv uden Kapital og overdrog sine Rettigheder og Forpligtelser til H. P. Hanssen, hvem han skyldte en betydelig Sum, og han overdrog dem atter til A lf red Dent.

Alfred Dent rejste derpaa i 1877 til Nord Borneo og bragte alle Dokumenter vedrorende Overdragelsen i Orden for efter sin Hjemkomst at tilbyde den engelske Regering at afstaa sin Rettigheder til England. Dent, Brother \& Co. maatte foreIøbig udrede alle deraf følgende Udgifter, og H. P. Hanssen fore 
de dermed i Forbindelse staaende Forretninger. Underhandlingerne med Regeringen trak i Lang(rag, og Udgifterne var allerede i $18 \times 0$ voksede til 40,000 Pund Sterling. Da tog Baron O ver beck, som vedvarende var Parthaver, imod Alfred Dents Vilje 1881 til Berlin og tilbød B is m a r ck Nord Borneo, men samtidig sorgede han for, at den engelske Gesandt i Berlin blev underrettet om hans Tilbud. Gesandten indberettede, som tilsigtet, straks Sagen, og dette satte Liv i G l a d s t o n e, som da var ved Roret. Regeringen gik nu ind paa Alfred Dents Fordringer. Nord-Borneo kom under engelsk Overhøjhed, og i Foraaret 1882 damnedes "British North Borneo \& Co., det store priviligerede Aktieselskab, som derefter bestyrede Nord Borneo med A Ifred Dent, der samtidig blev adlet, som Direktar.

Sir A lf red Dent, som han fra nu af tituleredes, blev snart tillige neget stærkt optaget af andre Forretninger. I Aarenes Lob blev han valgt til Direktor for "London Westm i n s t e r B a n k«, Englands xhlste og mest ansete Aktiebank, endvidere til Direktor for $" C h$ artered $B$ ank of India. Australien \& China»og til Direktor for "Royal Exh a nge«, Englands aldste og et af dets storste So-, Brand- og Livsforsikringsselskaber. Disse tre Poster beklædte han enduu efter Verdenskrigen. I nogle Aar var han desuden Prasident for "P eruvia n Corporation n med en aarlig Gage af 2000 Pund Sterling. Folgen af deme stærke Optagethed var, at han nasten helt overlod Ledelsen af De n $t, B$ roth e r \& Co. til H. P. Hanssen, som fortsatte dell inditil 1900, da han efter eget Ønske trak sig tilbage. Men efter Alfred Dents indtrangende Opfordring kom han ogsaa efter den Tid en Gang ugentlig paa Kontoret i London for at fore Tilsyn ned Forretningen og give sine Raad. Han kunde ogsaa i andre Henseender glade sig ved Alfred Dents fulde Fortrolighed og beholdt efter hans Onske Prokura for Firmaet til sin Dod for, som Alfred Dent sagde, "at holde sig i Reserve, hvis der skulde tilstøde ham selv noget«.

I London fandt $H$. P. Hanssen mange gamle Handelsvenner fra Østasien, ned hven han mødtes i "O rie n t a I C I u b\%. "Det er mig en stor Tilfredshed«, skrev han til mig et Par Aar" 
for $\sin$ Dod, "at jeg som Lidlanding har bevaret alle de Folks Tiltro og Venskab, der hørte til Huset Dent \& Co. enten som Partnere eller i Husets Employ." Hos Medlemmerne af den indenfor det engelske Handelsaristokrati hojtansete slagt De $n$, som han var noje knyttet til i over haivhundrede Aar, var han en altid velset Gast. I Halvfjerdserne lorl han sig naturalisere som engelsk Statsborger. I de sidste tyve Aar boede lian i sidcup ved Londion.

Da H. P. Hanssen i 1861 var Reprasentant for Dent \& Co, i Tientsin, blev han udnevnt til portugisisk Konsul, og senere i 1866, da han var indtraalt som Partner i Huset, til p or tug isisk Generalkonsul for Kina og Japan. Denne Stilling indtog han til 1873, da Generalkonsulatet blev overdraget til en indfodt Portugiser. Konsulatets runktioner bestor narmest $i$ at afgive Kendelser i Galdssager og Retstrætter. Dent \& Co., mellem hvis Chefer Stillingen saa at sige havie viret arvelig, havde altid Portugisere paa deres Kontorer, som agerede Tolk og skriver. Invrigt foregik Rettergangen efter engelsk Lov.

Inder sit lange Ophold i Kina kom H. P. Hanssen i Bernring med mange fremragende Mand. Sir Ro bert Hart, den bekendte (ieneral-Inspektor for det kinesiske Toldvæsen, havde han i sin Lngdon stiftet Bekendtskab med i Dent, Beale \& Co., livor han begyndte sin Lobebane. Han opretholdt Forbindelsen med ham, og Hart gav bl. a. senere beredvillig Mand, som H. P. Hanssen anbefalede til ham, gode stillinger indenfor det kinesiske Toldvæsen.

Den bekendte engelske General Gordon stiftede $H$. P. Hanssen Benkendtskab med under Taiping-Opstanden forst i Tredserne, da Generalen i nogen 'Tid boede hos Dent \& Co. i Shanghai. Paa Sandwichsgeme modte han i 1857 den foran omtalte Overberk, ell Apotekerson fra Lippe-Detmold, som flen Gang gik til Behring strodet for at kobe Pelsvark og Sperm-Olie af Indianeme. Nogle Aar senere traf de atter sammen som Kollegaer i Dent, Beale \& Co. I Mellemidien havde 
Overbeck fisket Perler ved Karolineme. I 1865 blev han af Huset sendt til New York for at kontrollere Bygningen af to nye Dampskibe. I Washington stiftede han Bekendtskab med en stiflatter af den svenskfodte Admiral Da h lg re n, som han senere agtede. I 1866 kom han tilbage til Honkong, hvor han efter Dent \& Co.s lald med skiftende Held kastedle sig ind $i$ vovede Spekulationer og forte et stort Hus. Sidst i Tredserne blev han udnevint til astrigsk-ungarsk (ieneralkonsul for Japan og Kina, og efter at han i 1873 havde indlagt sig store Fortjenester af de to Landes Repræsentation paa Verdensudstillingen i Wien, hvor H. P. Hanssen atter traf sammen med ham, blev han udnavnt til osterrigsk Baron. I de folgende Tider spekulerelle han i Patenter paa elektrisk Lys, i Petroleumsboring I Hamover, i Indvinding af Aluminium efter nye Metoder m. m., indtil han, som foran omtalt, fik afsluttet Traktaterne vedrørende Nord-Borneo. Med sine gamle Vemner fra Dent \& Co. vedblev han at staa i liorbindelse, og han forstod med sin sjældne Overtalelsesevne atter og atter at vække cleres Interesse for sine Foretagender. For H. P. Hanssen havde det den ubehagelige Folge, at han laante Baron Overbeck 4,900 Pund Sterling, hvoraf han aldrig fik Renter, og som, da Baron Overbeck i 1894 døde uden at efterlade sig l'ormue, ved hans Dod maatte anses som tabt. Baronessen, som havde en betydelig Særformue, var en intim Ungdomsveninde af Ceneral Lé e's Datter, som i forste Egteskab var gift med Pr i n s e n a f N oe r, i andet med General-Feltmarskal Gre v Wa l d e r s e e, der efter Overbecks Dod tog sig af hans Somner. Af disse var den ældste, som havde arvet Barontitlen, ved Verdenskrigens Udbrud i osterrigsk Tjeneste, de to yngste preusssiske Officerer.

Oberst $R$ a a $\mathbf{l}$ ø $f$ f stiftede H. P. Hanssen Bekendtskab med i 186i3, da han kom til Kina som Danmarks Repræsentant for at afslutte en Handelstraktat. H. P. Hanssen fik Lejlighed til at yde ham forskellige Tjenester, og de vedblev sellere at staa $i$ venskabelig Forbindelse. Korrespondancen fortsattes, efter at General Raasløff var bleven dansk Gesandt i Washington, 
hvorfra han gentagne Gange sendte $H$. P. Hanssen Gaver. Admiral s te n Bille lærte han ligeledes at kende i Kina i 186ī, da han kom ud for at faa Traktaten ratificeret. Admiralen gav senere "Det store Nordiske Telegrafselskab«s forste Bestyrere, Kaptajn Su en s on, D re yer og $\mathrm{H}$ el man $\mathrm{n}$ Anbefalingsskrivelser med til ham, og derved lærte han ogsaa dem at kende.

Uagtet H. P. Hanssen levede sin meste Tid mellem Englændere, fulgte han vedvarende Forholdenes Udvikling i Danmark og Nordslesvig med megen Interesse. I hans Bogsamling havde han et lille men godt Udvalg af danske Bøger, som jeg arvede efter ham. Biskop Mynsters Prædikener, Martensens Etik, Øhlenschlægers Tragedier, Paludan-Müllers Adam Homo, som han næsten kunde udenad, hørte til hans kæreste Læsning.

Fra 1876, da han kom tilbage til London,. til 1912, da han døde, besøgte han regelmæssigt sit Barndomshjem en Maanedstid hvert andet Aar. Efterhaanden, som hans Søskende docle, knyttede han intimere Forbindelse med deres Børn. Min Fader havde staaet ham særlig nær, og i Aarenes Løb givet ham mange Beviser paa sin Broderkærlighed. Efter hans Død fortsatte han Brevvekslingen med mine Søskende og mig, og han fulgte alle Grene af vor Familie med megen Interesse.

Naar han sad ene med os, fortalte han ofte interessante Træk fra sit rigt bevægede Liv. Dette gav for nogle Aar siden Anledning til, at jeg bad ham om at nedskrive sine Erindringer. Han lovede det, men erklærede samtidig, at jeg ikke maatte læse dem, mens han var i Live. Efter hans Død fik jeg dem tilsendt af Sir A l f red Dent. De fylder henved 500 tætskrevne Kvartsider, og det er paa Grundlag af dem, at jeg har skrevet denne lille Levnedstegning. Samtidig fik jeg alle mine Faders Breve til ham fra 1850 til 1892 tilsendt. Brevene fra 1864 har jeg 1914 - Halvhundredeaaret efter Krigen offentliggjort $\mathrm{i}$ "Hcjmdal «.

HI. P. Hanssen døde den 27. Marts 1912 paa Villaen "Longleat« i Sidcup ved London, hvor han havde haft sit Hjem i en længere Aarrække. Nogle Dage efter blev han jordfæstet 
ved Josephkirken $i$ denne By. Et talrigt Følge af gamle Venner, deriblandt mange, hvis Navne er højt ansete i den engelske Handelsverden, ledsagede ham til hans sidste Hvilested.

Hans Slægt bevarer ham i kærligt Minde.

H. P. Hanssen. 